\title{
Image analysis application in metallurgical engineering and quality control
}

\author{
Z. Odanović ${ }^{1}$, M. Djurdjević ${ }^{2}$, G. Byczynski ${ }^{2}$, \\ B. Katavić ${ }^{3} \&$ V. Grabulov ${ }^{1}$ \\ ${ }^{1}$ IMS Institute, Serbia \\ ${ }^{2}$ Nemak Linz, Austria \\ ${ }^{3}$ Institute Goša, Serbia
}

\begin{abstract}
Image analysis (IA) is widely used in different areas of science such as medicine, biology and engineering. Quantitative measuring by image analysis has also found application in metallurgical engineering, especially in analyzing metallographic microstructures. The measuring of different microconstituents dimensions based on image analysis, performed in metallurgical investigations is presented in the paper. Determination of the brittle phase content in the function of the heat treatment temperature for the heat resistant Ni-Cr-Co-W alloy, with the aim of obtaining optimal microstructure for repair welding are presented. Results have shown that the best effect of the brittle phases dissolving is obtained at the temperature of $1250^{\circ} \mathrm{C}$. Investigation of the effects of $\mathrm{Si}(1-10 \%)$ and $\mathrm{Cu}(0.5-4.5 \%)$ content, in the cast $\mathrm{Al}$ alloy for automotive application, on secondary dendrite arm spacing (SDAS) in the structure was performed. Results have shown that the higher silicon and copper contents reduced the size of the SDAS, which directly enable better mechanical properties of the cast product. The effect of different energy inputs, in the steel arc welding process, on the dimensions and geometry of the zones in a cross section of the welded joint was investigated. The heat affected zone (HAZ) of the welds is critical for the mechanical properties and weld quality and it is directly dependent on the energy input. The area and width of the HAZ for different heat inputs, from 0.4 to $1.4 \mathrm{~kJ} / \mathrm{mm}$, were measured by the IA. The obtained results have shown direct dependence of the measured dimensions from the energy input. The applied methodology enables weld quality control in the case of the automatic welding processes. All presented experimental results are based on a large number of measurements. A statistical analysis was performed and a high correlation of the results was obtained. For the each of the presented investigations and analyzed phenomenon, a statistical mathematical model is suggested with the boundary conditions defined by the investigated intervals of variables.
\end{abstract}

Keywords: image analysis, $\mathrm{Ni-Cr}-\mathrm{Co}-\mathrm{W}$ alloys, cast Al alloys, steel welds. 


\section{Introduction}

Image analysis (IA) is widely used in different areas of science such as medicine, biology and engineering. Quantitative measuring by image analysis has served the automotive, aerospace, semiconductor, metal fabrication, foundry, welding, or other related materials design, fabrication or testing industry. IA also found application in metallurgical engineering, especially in analyzing metallographic microstructures. Structure measurements as cast structure properties, failure analysis, welding structures measurement have received considerable attention in recent years, partly because of development of stereological methods and the importance made in image analysis. Quantitative measurement of microstructure is of great importance in quality control studies as well as in structure property control. For many years, metallurgists have primarily relied on qualitative descriptions of microstructures or rating based on comparison charts. In general, comparison charts lack the sensitivity needed to accurately define differences between samples. The accuracy of this methodology significantly depends on the operator's experience, knowledge and ability to properly estimate some structural features. It is a very subjective method and obtained results are the matter of estimations.

Development of automatic image analysis has greatly increased the use of stereological principles for determining microstructure characteristics. These devices reduce the time necessary for manual measurements, improve accuracy of statistical measurements, reduce time, and eliminate the influence of operator estimation to the minimum level. Application of this apparatus required greater attention to sample preparation, since the software lacks the human ability to separate microstructure features that are not clearly defined.

Quick and easy detection and selection of the microconstituents by shape, size, colour and other criteria is allowed by the IA application. It is applicable for determination of the metal grain size, phase content in powder or non ferrous metals, content of the martensite, pearlite, ferrite, austenite in steel microstructure, shape and content of the graphite in the cast iron, etc.

Quantitative measurements are of great value to the many fields of metallurgy as this paper has demonstrated. Three different metallurgical problems were analysed based on the measuring of the linear or/and areal dimensions of the microstructural/macrostructural components by the IA in relation to the process parameters. Area measuring of the brittle phase in steel microstructure and the area of the weld metal and heat affected zone in the macrostructure of the weld joint were performed. Linear dimensions as secondary dendrite arm spacing (SDAS) in a cast Al alloy and weld metal and heat affected zone width were also carried out. Effects of heat treatment temperature on the brittle phase content in the microstructure of the high temperature alloy, properties of the cast microstructure in function of the $\mathrm{Al}$ alloy chemical composition and effects of the heat input on the steel weld joint dimensions were investigated in this work. All tests were performed by a light optical microscope with an automatic image analyser. 


\section{Experimental}

\subsection{Brittle phase content in the Ni-Cr-Co-W alloy microstructure}

Determination of the brittle phase content in the microstructure of the heat resistant Ni-Cr-Co-W alloy (Supetherm) tube was performed. Centrifugally cast riser tube from an ammonia plant was exposed for about 70000 hours at an operating temperature of $850^{\circ} \mathrm{C}$ and was fractured. For weld repairing of the tube it was necessary for the alloy to be previously prepared. The usual way for obtaining optimal microstructure for repair welding of the investigated alloys is high temperature dissolving of the brittle phases. For defining the optimal temperature for heat treatment a diffusion annealing at temperatures in the $50^{\circ} \mathrm{C}$ interval, from $1150^{\circ} \mathrm{C}$ to $1250^{\circ} \mathrm{C}$ during 1 and 3 hours was performed. The chemical composition of the analysed alloy and mechanical properties in the untreated alloy are presented in Tables 1 and 2.

Table 1: $\quad$ Chemical composition of analysed Supertherm alloy (in mass. \%).

\begin{tabular}{|c|c|c|c|c|c|c|c|c|c|}
\hline $\mathrm{C}$ & $\mathrm{Mn}$ & $\mathrm{S}$ & $\mathrm{P}$ & $\mathrm{Si}$ & $\mathrm{Ni}$ & $\mathrm{Cr}$ & $\mathrm{Co}$ & $\mathrm{W}$ & $\mathrm{Fe}$ \\
\hline 0.48 & 0.54 & $<0.02$ & $<0.02$ & 1.38 & 34.9 & 25.8 & 15.7 & 4.93 & rest \\
\hline
\end{tabular}

Table 2: Mechanical properties of Supertherm alloy in non-treated condition.

\begin{tabular}{|c|c|c|}
\hline $\begin{array}{c}\text { Tensile } \\
\text { strength }\end{array}$ & $\begin{array}{c}\text { Absorbed energy } \\
\text { KV300/1.5 }\end{array}$ & Hardness \\
\hline $\mathrm{MPa}$ & $\mathrm{J}$ & HV 30 \\
\hline 410 & 1.5 & 304 \\
\hline
\end{tabular}

Samples for investigation were prepared for optical microscopy by the classic method of grinding and polishing. Etching was performed in Aqua regia. The light optical microscope has been used. Quantitative metallographic measurements were based on the image analysis. The heat treatment effects on the quantity of brittle $(\sigma)$ phase and carbides in the microstructure were analysed. Based on the black/white contrast, the total area of brittle phases was determined by image analysis. Applied magnification was 200 times. Ten measurings were performed at each sample, and then the highest and lowest value were rejected and the mean value of the remaining eight measuring were presented as a result.

\subsection{Properties of the cast Al alloys microstructure}

The most important practical aspect of the cast dendrite structure is the secondary dendrite arm spacing (SDAS) that represents the distance between secondary dendrites in the solidifying structure of cast metals and alloys. In order to investigate the impact of silicon and copper on the size of the SDAS in Al-Si- 
$\mathrm{Cu}$ alloys, the contents of these two elements have been varied between 1.3 and 9.7 wt.\% Si, while copper additions were varied between 0.37 and 4.7 wt.\%.

The investigations were performed using Al-Sil1 alloy with the trace of $\mathrm{Cu}$, $\mathrm{Mg}$ and other elements, which had been diluted by adding certain amount of pure aluminium in order to reach designed content of silicon. The chemical compositions of the resulting eleven alloys, as determined using Optical Emission Spectroscopy (OES) are presented in Table 3.

Table 3: Chemical compositions of investigated Al-Si alloys with different content of silicon.

\begin{tabular}{|c|c|c|c|c|c|c|c|c|c|c|c|}
\hline Alloy & 1 & 2 & 3 & 4 & 5 & 6 & 7 & 8 & 9 & 10 & 11 \\
\hline $\mathrm{Si}$ (wt.\%) & 10.99 & 9.71 & 8.59 & 7.57 & 6.97 & 6.05 & 4.70 & 3.72 & 2.75 & 2.06 & 1.30 \\
\hline $\mathrm{Al}$ (wt.\% & rest & rest & rest & rest & rest & rest & rest & rest & rest & rest & rest \\
\hline
\end{tabular}

$\mathrm{Fe}=0.09-0.13, \mathrm{Cu}=0.001-0.002, \mathrm{Mn}=0.02-0.04, \mathrm{Mg}=0.17-0.32, \mathrm{Zn}=0.006-0.009$.

In order to analyse the effect of the various content of copper on the size of the SDAS nine synthetic Al-Si-Cu compositions were produced by melting a charge of Al-6 wt.\%Si-0.002 wt.\% Cu base alloy, with the addition of various amounts of pure copper. Table 4 shows the chemical composition of the resulting alloys.

Table 4: Chemical compositions of investigated Al-Si-Cu alloys with different content of copper.

\begin{tabular}{|c|c|c|c|c|c|c|c|c|c|}
\hline Alloy & 1 & 2 & 3 & 4 & 5 & 6 & 7 & 8 & 9 \\
\hline $\mathrm{Si}$ (wt.\%) & 6.02 & 6.09 & 6.19 & 6.25 & 6.15 & 6.07 & 6.10 & 6.21 & 6.17 \\
\hline $\mathrm{Cu}(w t . \%$ & 0.37 & 0.76 & 1.42 & 1.76 & 2.13 & 2.23 & 2.60 & 3.20 & 4.71 \\
\hline $\mathrm{Al}$ (wt.\% $\%$ & rest & rest & rest & rest & rest & rest & Rest & rest & rest \\
\hline
\end{tabular}

$\mathrm{Fe}=0.07-0.08, \mathrm{Mn}=0.002, \mathrm{Mg}=0.21-0.30, \mathrm{Zn}=0.004-0.005$.

Previously prepared samples for each targeted alloys are firstly charged in the ceramic cups, loaded in an electric resistance furnace and melted. During all experiments the melt temperature was kept constant at the $700^{\circ} \mathrm{C} \pm 5^{\circ} \mathrm{C}$. After melting down, all samples with masses of approximately $80 \mathrm{~g} \pm 2 \mathrm{~g}$ where left to solidify under the same conditions. The thermoelement has been inserted into test sample in order to determine the cooling rate. The temperature range between liquidus and solidus temperature divided with total solidification time has been used to calculate the rate of solidification. The cooling rate for all samples was $0.15^{\circ} \mathrm{C} / \mathrm{sec}$.

Solidified cylindrical samples are sectioned vertically. One half of the sample has been used for chemical analysis while the other half has been used for quantitative measurements of the SDAS by IA. Metallographic samples were prepared by standard grinding and polishing procedures. The light optical microscope has been used in this work for the SDAS measurement. 
The SDAS is a measure of the length scale between two adjacent SDAS and it is usually an order of magnitude smaller than the primary arm spacing. In this work the line intercept method was utilized to measure the SDAS. The applied magnification was 25 times. The size of the SDAS has been obtained as an average value of at least 10 measurements.

\subsection{Zones dimensions in cross section of the steel welded joint}

The steel weld joint consists of different zones, such as: weld metal, heat affected zone and base metal. The heat affected zone (HAZ) of the welds is critical for the mechanical properties and weld quality and it is directly dependent on the energy input of the heat source. The area and the width of the HAZ and weld metal (WM) for different heat inputs in arc welding of the steel plates were quantitatively measured by image analysis.

Five trial bead on plate welds have been produced with the various heat inputs. Test pieces 6x150x300 mm of low alloy Q\&T, Ni-Cr-Mo (HY-100) steel have been used as the base plates. The chemical composition and mechanical properties of the steel are given in Tables 5 and 6 .

Table 5: $\quad$ Chemical composition of HY-100 steel plate and welding wire.

\begin{tabular}{|c|c|c|c|c|c|c|c|c|c|l|}
\hline & \multicolumn{10}{|c|}{ Chemical Composition (mass. \%) } \\
\hline & $\mathrm{C}$ & $\mathrm{Si}$ & $\mathrm{Mn}$ & $\mathrm{P}$ & $\mathrm{S}$ & $\mathrm{Cr}$ & $\mathrm{Ni}$ & $\mathrm{V}$ & $\mathrm{Mo}$ & $\mathrm{Fe}$ \\
\hline plate & 0.11 & 0.31 & 0.27 & 0.010 & 0.004 & 1.01 & 2.64 & 0.08 & 0.28 & rest \\
\hline $\begin{array}{c}\text { welding } \\
\text { wire }\end{array}$ & 0.09 & 0.75 & 1.50 & $/$ & $/$ & $/$ & 1.10 & $/$ & $/$ & rest \\
\hline
\end{tabular}

Table 6: $\quad$ Mechanical properties of HY-100 steel plate.

\begin{tabular}{|c|c|c|c|c|}
\hline $\begin{array}{c}\text { Yield } \\
\text { Strength } \\
\mathrm{Rp}_{0.2}\end{array}$ & $\begin{array}{c}\text { Tensile } \\
\text { Strength } \\
\mathrm{Rm}\end{array}$ & $\begin{array}{c}\text { Elongation in } \\
50 \mathrm{~mm} \\
\mathrm{~A} 5\end{array}$ & $\begin{array}{c}\text { Charpy V-Notch } \\
\text { Impact ISO-V } \\
\text { min. }\end{array}$ & Bending \\
\hline $\mathrm{MPa}$ & $\mathrm{MPa}$ & $\%$ & $\mathrm{~J}$ & $\alpha=180 \mathrm{o}$ \\
\hline min. 690 & $740-940$ & $\min .16$ & 118 at $293 \mathrm{~K}$ & $\mathrm{~d}=3.0 \mathrm{a}^{*}$ \\
\hline
\end{tabular}

The single pass bead on plate GMA welds were made on an automatic welding device, with which a specified welding speed could be accurately controlled. The shielding $\mathrm{CO}_{2}$ gas flow was $0.1 \mathrm{dm}^{3} \mathrm{~s}^{-1}$. Chemical composition of an $\varnothing 1.2 \mathrm{~mm}$ welding wire is given in Table 5. Welding parameters are listed in Table 7.

The width and area of weld metal and HAZ were measured on the samples sectioned from the transverse cross sections of the welded joint. The surfaces of the samples are routinely grounded and polished. The samples were etched in 3\% Nital solution and were examined on the optical microscope with image analysis equipment. The quantitative measuring of the HAZ area is determined based on the black/white contrast. The width of the HAZ was measured by the linear 
Table 7: Welding conditions for trial bead on plate welds.

\begin{tabular}{|c|c|c|c|c|c|}
\hline Sample & $\begin{array}{c}\text { Arc } \\
\text { Voltage }\end{array}$ & $\begin{array}{c}\text { Welding } \\
\text { Current }\end{array}$ & $\begin{array}{c}\text { Welding } \\
\text { Speed }\end{array}$ & $\begin{array}{c}\text { Speed of } \\
\text { Welding Wire }\end{array}$ & Heat Input \\
\hline & V & A & mm s-1 & mm s-1 & KJ mm-1 \\
\hline 1 & 27 & 260 & 16.7 & 165 & 0.4 \\
\hline 2 & 28 & 198 & 9.3 & 140 & 0.6 \\
\hline 3 & 30 & 182 & 6.2 & 104 & 0.9 \\
\hline 4 & 28 & 196 & 5.1 & 117 & 1.1 \\
\hline 5 & 29 & 232 & 5.0 & 146 & 1.4 \\
\hline
\end{tabular}

intercept method. The size of the width and area of weld metal and HAZ has been obtained as an average value of at least 5 measurements.

\section{Results and discussion}

\subsection{Heat treatment effects on the Ni-Cr-Co-W alloy microstructure}

A lot of trial and error is involved when it comes to repair welding of service exposed high temperature cast materials and, depending on the source, different weld repair strategies are proposed and applied. One of the methods used to enhance weldability is solution annealing before welding. The data from literature showed that embrittlement caused with brittle phases, as secondary carbides and $\sigma$ - phase, could be eliminated and original ductility restored by a solution annealing heat treatment at $1065^{\circ} \mathrm{C}$ during two hours [1]. This data existed for cast alloy HP, but for investigated alloy Supertherm was not found. Therefore, in the present work, the aim has been to assess the optimal temperature for solution annealing for preparing alloy for weld repairing.

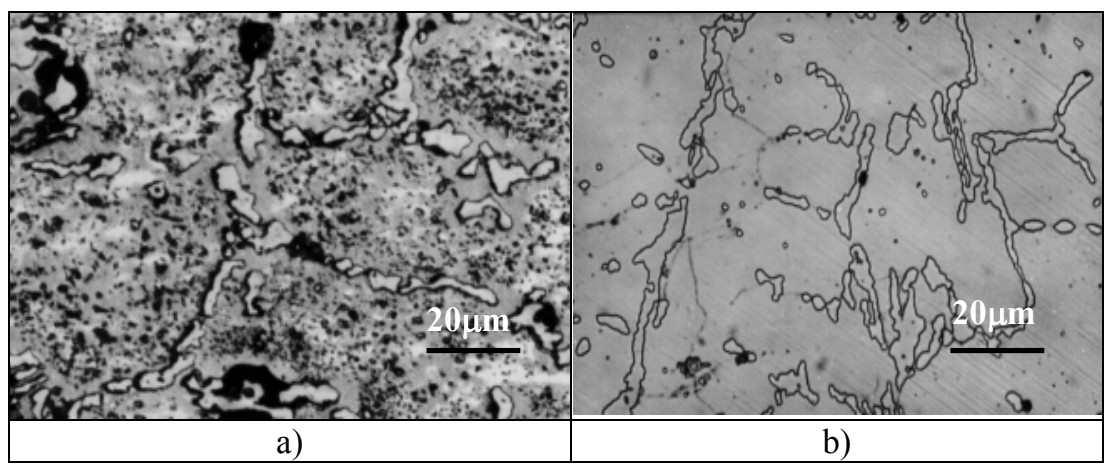

Figure 1: Microstructure samples of the Supertherm alloy investigated by the IA, a) without heat treatment b) after heat treatment at $1250^{\circ} \mathrm{C} / 1 \mathrm{~h}$, etched in Aqua regia. 
The samples of the microstructure for investigations are presented in Figure 1. The sample of the as received microstructure without high temperature heat treatment is shown on Figure 1a), while sample of the treated microstructure at $1250^{\circ} \mathrm{C}$ for $1 \mathrm{~h}$ is shown in Figure $1 \mathrm{~b}$ ). The areas of the brittle phases at the grain boundaries and inside the grain were measured.

The results of the quantitative metallographic measurements based on the image analysis are presented. The effects of heat treatment temperature on the quantity of brittle phases as $\sigma$ - phase and carbides, are presented by diagram in Figure 2. It is evident that with the increase of the annealing temperature there is a decrease of the total area of the $\sigma-$ phase and carbide particles in relation to untreated condition. Such behaviour is a result of their dissolution in the austenite - $(\gamma)$ phase.

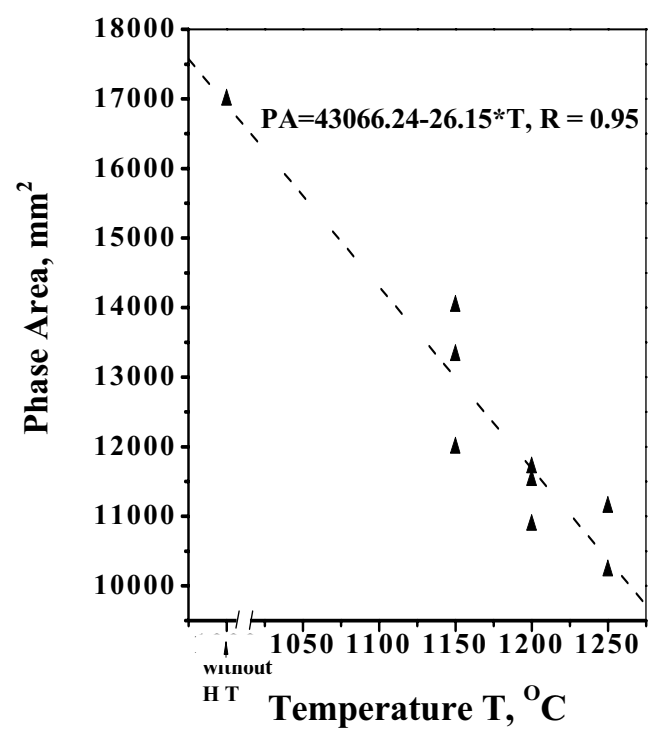

Figure 2: The effect of heat treatment temperature on the overall quantity of $\sigma$ phase and carbides particles

From the result obtained by IA, it is obvious that the temperature of $1250^{\circ} \mathrm{C}$ offers the best effects of brittle phases dissolution, and therefore it could be suggested for enhancing weldability and for preparation for repair welding of an investigated material. It has to be noted that this temperature is close to the temperature of liquation of certain Supertherm alloy microconstituents. Therefore, an annealing temperature of between $1150^{\circ} \mathrm{C}$ and $1200^{\circ} \mathrm{C}$ is suggested for heat treatment of an investigated alloy.

The results of regression analysis has shown high correlation coefficient $\mathrm{R}$ between 0.95 and 0.98 , which indicates that the obtained results could be applied for determination of the analysed values in the analysed temperature interval. 


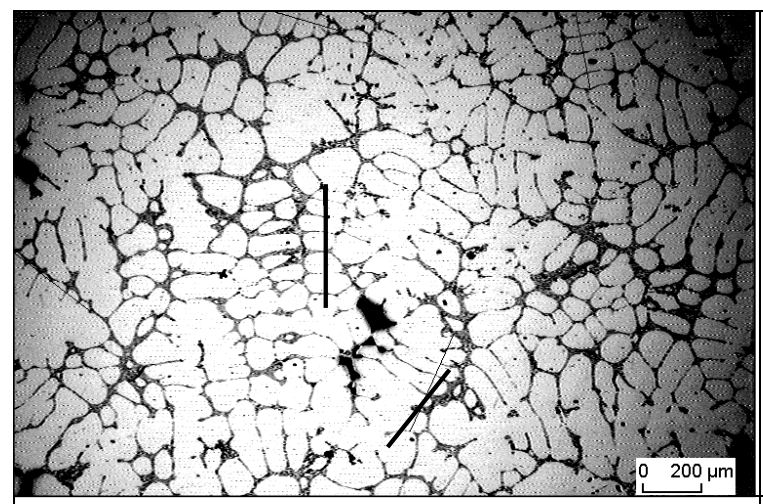

a)

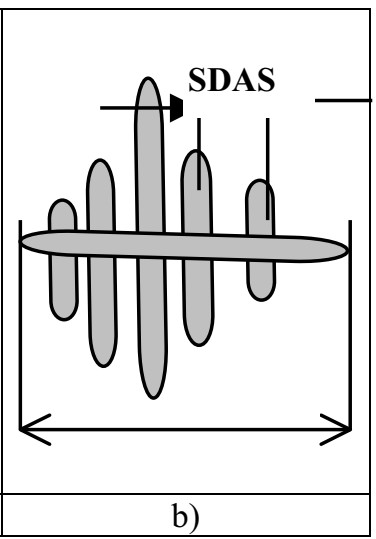

b)

Figure 3: Sample of the analysed aluminium-silicon alloy microstructure a) and b) schematic representation of dendrites showing the difference between primary dendrite arm spacing (DAS) and measured secondary dendrite arms spacing (SDAS).

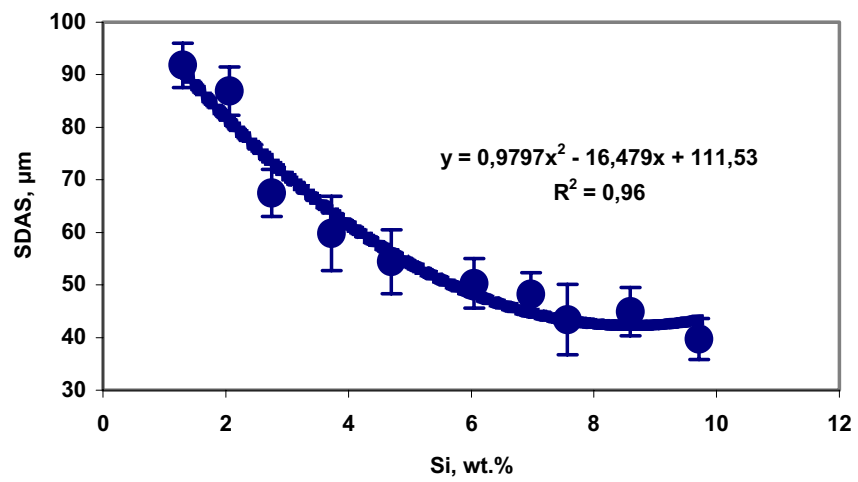

Figure 4: The effect of the various silicon content on the size of the SDAS. There is appreciable refining effect as the content of silicon varied between 1 and 8 weight percent. When the content of silicon increase above $8 \mathrm{wt} . \%$, this effect is insignificant.

\subsection{Secondary dendrite arm spacing (SDAS) in cast Al alloys}

A comprehensive understanding of melt quality is of paramount importance for the control and prediction of actual casting characteristics. The most important practical aspect of the cast dendrite structure is the secondary dendrite arm spacing (SDAS) that represents the distance between secondary dendrites in the solidifying structure of cast metals and alloys. This quantity is significant because it has been shown that many mechanical properties can be related to it, with the best properties always associated with the smallest SDAS [2]. A sample of the analysed aluminium-silicon alloy microstructure and schematic 
representation of dendrites showing primary dendrite arm spacing (DAS) and measured secondary dendrite arms spacing (SDAS) are presented in Figure 3.

A well known effect of varying cooling rates on the size of the SDAS is effusively exploited in the literature. In addition, the effect of alloying elements on the size of the SDAS by aluminium-silicon alloys was not so extensively investigated. Only a few researchers have examined the effect of variation in the Al alloy composition on the size of the SDAS [3, 4].

The influence of various content of the silicon and copper on the size of the SDAS in Al alloy is presented in Figures 4 and 5. The each point on figures corresponds to the average value of the SDAS based on the ten measurements. Vertical bars represent the standard deviations for each series of measurements.

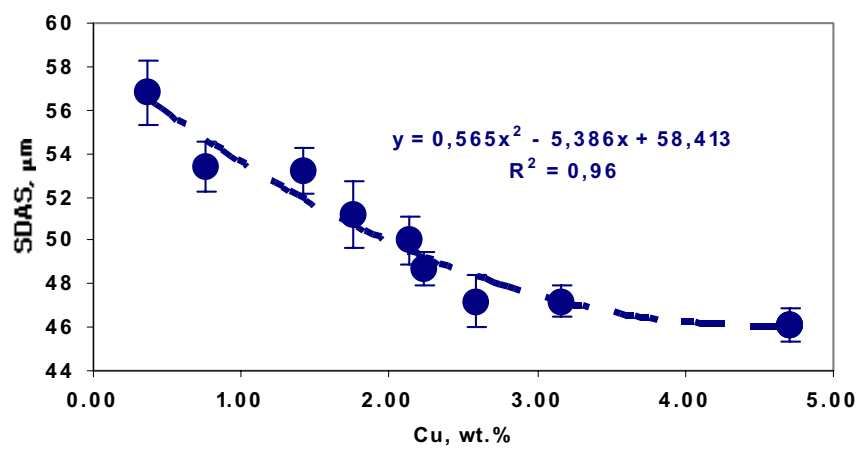

Figure 5: The effect of the various copper content on the size of the SDAS. The increases in the copper content from 0 to 3 weight percent refine considerably the size of the SDAS. Any increase above 3 wt.\% of copper refine the dendrite but at a much lower rate.

The higher silicon and copper contents reduced the size of the SDAS. Dependence between the SDAS and silicon or copper content could be expressed by linear equations with high correlation coefficient.

Measurement done by image analysis confirmed that the average size of the SDAS decrease from $91.8 \mu \mathrm{m}$ to $39.7 \mu \mathrm{m}$ according to addition of silicon from 1 to $10 \mathrm{wt}$. \% respectively. The effect is more significant until silicon reaches the content of $8 \mathrm{wt} . \%$. Further increase in the content of silicon has almost no effect on the size of this microconstituent. A similar, but considerably smaller effect can be recognized by the addition of copper in the $\mathrm{AlSiCu}$ melt. The data presented in Figure 6 shows that the size of the SDAS slightly decreases from $56.8 \mu \mathrm{m}$ to $46.1 \mu \mathrm{m}$ when the content of copper in the AlSiCu melt increase to approximately $4.7 \mathrm{wt} \%$. Theses results are not unexpected. It is well known from the literature that the size of the dendrites is, beside the cooling rate of solidification, dependent on the level of alloying elements present in the melt [2]. From the result it is evident that the effect of the same content of copper is slightly smaller that that of the same content of silicon.

Dependence between the SDAS and silicon or copper content are expressed by polynomial equations with high correlation coefficient $\mathrm{R}=0.96$. The presented 
equations could be used for SDAS prediction for different $\mathrm{Si}$ or $\mathrm{Cu}$ contents in the investigated intervals.

\subsection{Steel weld joint dimensions}

The measured values by IA, as linear and area weld joint dimensions, in the cross section of the bead on plate welded joint in the arc welding process, are presented in Figure 6.

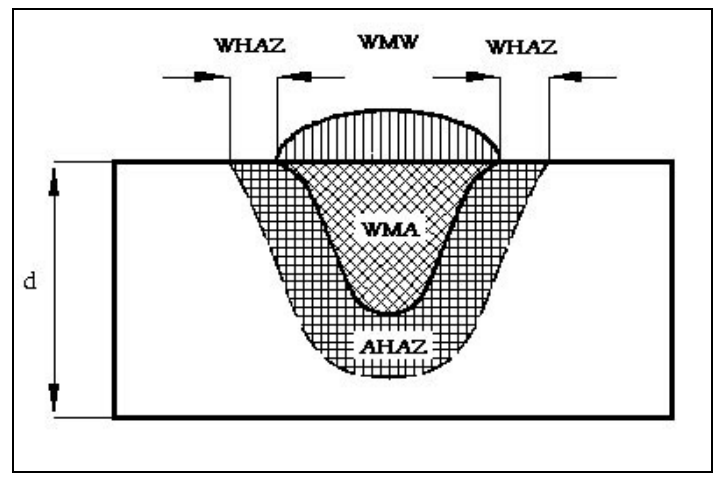

Figure 6: Schematic presentation of the measured bead on plate weld dimensions, WMW - weld metal width, WHAZ - width of the HAZ, WMA - weld metal area, AHAZ - area of the HAZ.

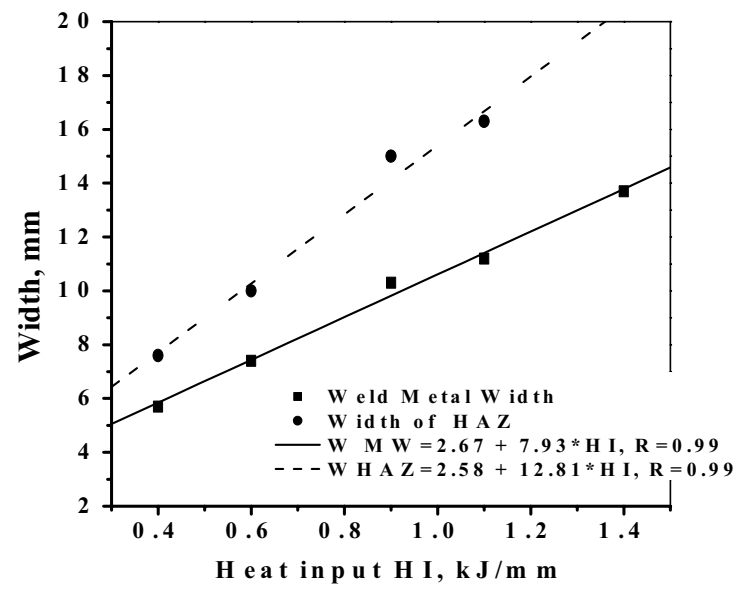

Figure 7: $\quad$ Measured linear dimensions of the steel weld joint as a function of the heat input HI. WMW - weld metal width, WHAZ - width of the HAZ.

The result of the measured critical weld dimensions as: WMW - weld metal width, WHAZ - width of the HAZ, WMA - weld metal area, AHAZ - area of 
the HAZ for different heat inputs (HI) during arc welding, from 0.4 to $1.4 \mathrm{~kJ} / \mathrm{mm}$, are presented in Figures 7 and 8 .

The obtained results have shown direct dependence of the measured dimensions from the energy input. Measured widths, of the WM and HAZ are increased with heat input increasing, as presented on Figure 8. The same dependence is observed for WM and HAZ area in relation to the heat input (Figure 8). It is known from the literature that dimensions of the HAZ directly depend of heat input [5]. For the measured results by IA, correlation coefficients of the linear regression equations are calculated. The high correlation coefficients $\mathrm{R}$, with value of 0.99 are obtained for all performed measurements.

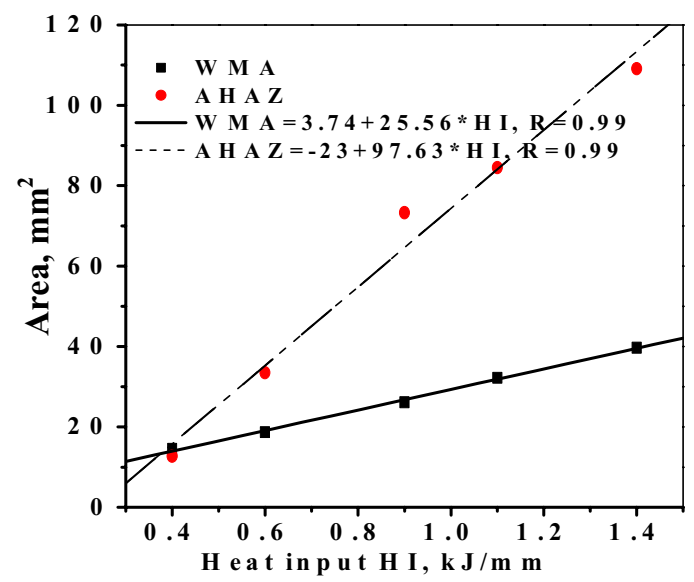

Figure 8: Measured area dimensions of the steel weld joint as a function of the heat input HI. WMA - weld metal area, AHAZ - area of the HAZ.

The presented methodology based on the IA measurements enables quality control of the welds joins in a case of the weld qualification and for the periodical controls in the automatic welding processes.

\section{Conclusions}

Quantitative measuring by image analysis applied in metallurgical engineering is presented. Three different metallurgical problems were analysed based on the measuring of the linear or/and areal dimensions of the microstructural/ macrostructural components by the IA in relation to the process parameters as:

Determination of the brittle phase content in the function of the heat treatment temperature for the heat resistant Ni-Cr-Co-W alloy, with the aim of obtaining optimal microstructure for repair welding are presented. Results have shown that the best effect of brittle phases dissolving is obtained at the heat treatment temperature interval from $1150^{\circ} \mathrm{C}$ to $1250^{\circ} \mathrm{C}$. 
Investigation of the effects of $\mathrm{Si}(1-10 \%)$ and $\mathrm{Cu}(0.5-4.5 \%)$ content, in the cast Al alloy for automotive application, on secondary dendrite arm spacing (SDAS) in the structure was performed. Results have shown that the higher silicon and copper contents reduced the size of the SDAS, which directly enable better mechanical properties of the cast product.

The effect of different energy inputs, in a steel arc welding process, on the dimensions and geometry of the steel welded joint was investigated. The heat affected zone (HAZ) of the welds is critical for the mechanical properties and weld quality and it is directly depended of the energy input. The area and the width of the HAZ for different heat inputs, from 0.4 to $1.4 \mathrm{~kJ} / \mathrm{mm}$, were measured by the IA. The presented methodology enables quality control of the welds joins in a case of the weld qualification and for the periodical controls in the automatic welding processes.

All presented experimental results are based on a large number of areal or linear dimensions measurements by the IA. High correlation coefficients for the regression equations of the results were obtained for the each of the presented investigations.

\section{Acknowledgement}

A part of this work was carried out in a scope of the project 19023: "Development of the new repair welding technologies for intervention maintain thermo energetic plants" supported by the Ministry of Science of the Republic of Serbia

\section{References}

[1] Vekeman J., De Waele M., "Repair welding of HP-40Nb", IIW Doc. $I X$ 2266-08, (2008)

[2] Odanović Z., Djurdjević M., Grabulov V., Sokolowski J.: "Influence of Si Content and Cooling Rates on the Size of SDAS and the Latent Heat Released in Al-Si(5-11)-Cu1 Alloys", Proceedings of European Metallurgical Conference EMC 2007, Dusseldorf, 2007, ISBN 978-3940276-07-0, pp. 61.-73.

[3] Spear R.E. and G. R. Gardner, Dendrite cell size, AFS Transactions 71 (1963) pp. 209-215.

[4] Zang B., Garro M. and Tagliano C., "Dendrite arm spacing in aluminium alloy cylinder heads produced by gravity semi-permanent mold", Metallurgical Science and Technology, Vol.21, No. 1, June 2003, pp. 3-9.

[5] Alberry P. J., Sensitivity Analysis of Half-Bead and Alternative GTAW Techniques, Welding Research Supplement, 1989, (11), pp. 442s-451s. 